\title{
Silencing insulin-like growth factor-1 receptor expression inhibits gastric cancer cell proliferation and invasion
}

\author{
JIE GE ${ }^{1}$, ZIHUA CHEN $^{1}$, JIN HUANG $^{2}$, WEIJIE YUAN ${ }^{2}$, ZHENGHAO DEN $^{3}$ and ZHIKANG CHEN ${ }^{1}$ \\ Departments of ${ }^{1}$ Gastrointestinal Surgery, ${ }^{2}$ Oncology and ${ }^{3}$ Pathology, Xiangya Hospital, \\ Central South University, Changsha, Hunan 410008, P.R. China
}

Received December 30, 2013; Accepted September 18, 2014

DOI: $10.3892 / \mathrm{mmr} .2014 .2746$

\begin{abstract}
The oncoprotein insulin-like growth factor-1 receptor (IGF-1R) has previously been shown to promote tumorigenesis. Overexpression of IGF-1R is considered to be a critical prerequisite for malignant transformation in numerous human cancers. Therefore, targeting IGF-1R for cancer therapy has gained a lot of interest. In the present study, an RNA interference (RNAi)-mediated IGF-1R gene silencing approach was conducted in BGC823 gastric cancer cells. The tumorigenic and malignant properties of the cells were assessed, in response to reduced IGF-1R expression. Notably, IGF-1R depletion not only inhibited gastric cancer cell growth, resulted in $G_{1}$ cell cycle arrest and consequently led to apoptosis, but also suppressed cancer cell motility and invasion. The findings of the present study are the first, to the best of our knowledge, to suggest that RNAi-based IGF-1R silencing may be a potential and promising therapeutic strategy for gastric cancer treatment.
\end{abstract}

\section{Introduction}

The insulin-like growth factors 1 and 2 (IGFs) were initially discovered in the mid-1950s, as mediators of growth and developmental processes (1). IGFs have been shown to recapitulate numerous functions of insulin, including increasing glucose metabolism and transport, inhibiting lipolysis, and accelerating lipid, glycogen and protein syntheses (2). The role of IGFs in tumorigenesis has attracted a lot of attention since the early 1990s, when it was demonstrated that a lack of insulin-like growth factor-1 receptor (IGF-1R) conferred resistance to viral and cellular oncogene-induced transformation in R-cells (3). Later studies showed that enhanced IGF-1R expression is a pre-requisite for cells about to undergo

Correspondence to: Dr Zhikang Chen, Department of Gastrointestinal Surgery, Xiangya Hospital, Central South University, 87 Xiangya Road, Changsha, Hunan 410008, P.R. China E-mail: chenzhikang2013@126.com

Key words: insulin-like growth factor-1 receptor, RNA interference, gastric cancer, cell growth, apoptosis, metastasis proliferation or transformation (4). In addition, amplification or overexpression of IGF-1R has been detected in numerous human cancers, including breast, kidney, prostate, lung and stomach cancers (5). Therefore, targeting IGF-1R for a potential therapeutic strategy in human cancers has gained considerable interest.

The discovery of RNA interference (RNAi) was initially presented in 1998 (6), and subsequently the technology was suggested to be a novel therapeutic strategy for treating human diseases (7). Small interfering RNA (siRNA), a class of double-stranded RNA ranging from 20-25 base pairs in length, can recruit the RNA-induced silencing complex to target genes with high sequence specificity, and consequently either suppress translation or cause mRNA degradation (8). Human cancer is a complex consequence of the interplay between oncogenes that promote tumor cell growth or metastasis, and tumor suppressor genes that do the opposite. Therefore, inhibition of oncogene expression and elevation of tumor suppressor expression, through siRNA-based therapeutics, may be a potential therapeutic strategy for cancer treatment. Previous studies have shown that the in vivo delivery of siRNAs targeting survivin, androgen receptor, enhancer of zeste homolog 2, polo-like kinase 1, or vascular endothelial growth factor, in prostate cancer, markedly reduced tumor cell growth and metastasis (9). The tumor suppressor gene p53 is frequently mutated to gain oncogenic activity in $>50 \%$ human cancers, and is down-regulated in other cancers by its negative regulators, which include transforming protein E6 of human papilloma virus and mouse double minute 2 homolog (MDM2) (10). RNAi-based inhibition of mutant p53 or MDM2 have previously been shown to effectively repress tumorigenesis in human cancer cells and a mouse model $(11,12)$.

A previous study demonstrated that IGF-1R is highly expressed in gastric cancer (GC) and is associated with tumor size, quantity of stroma, depth of wall invasion, lymph node metastasis, TNM (Tumor size/lymph Node/Metastasis) stages and differentiation status (13). The present study aimed to further investigate whether RNAi-based IGF-1R depletion could affect the tumorigenic and metastatic activity of the BGC823 GC cell line. These findings suggested a role for IGF-1R in carcinogenesis; however, to the best of our knowledge, the role of IGF-1R has not been investigated in gastric cancer. Therefore, the objective of the present study was to elucidate the role of IGF-1R in gastric cancer. 


\section{Materials and methods}

Cell culture. The BGC823 GC cell line was purchased from the Xiangya School of Medicine Central Experiment Laboratory (Changsha, China). The cells were cultured in Dulbecco's modified Eagle's medium (DMEM; Gibco Life Technologies, Carlsbad, CA, USA), supplemented with $10 \%$ fetal bovine serum (FBS; Gibco Life Technologies), $100 \mathrm{U} / \mathrm{ml}$ penicillin and $0.1 \mathrm{mg} / \mathrm{ml}$ streptomycin, at $37^{\circ} \mathrm{C}$ in a $5 \% \mathrm{CO}_{2}$ humidified atmosphere.

Antibodies. The primary antibodies against IGF-1R and $\beta$-actin, were purchased from Abcam (Cambridge, UK), and Sigma-Aldrich (St Louis, MO, USA), respectively. Thegoat anti-mouse Immunoglobulin $\mathrm{G}(\mathrm{IgG})$ and goat anti-rabbit $\operatorname{IgG}$ secondary antibodies were purchased from Kirkegaard \& Perry Laboratories, Inc. (Gaithesburg, MD, USA).

MTT assay. BGC823 cell suspensions were seeded $\left(4 \times 10^{4}\right.$ cells/well) in a 96 well plate. Following a $16 \mathrm{~h}$ culture, the cells were infected with pSUPER-IGF-IR-siRNA2 or pSUPER-control-siRNA2 (Genechem, Shanghai, China), or treated with phosphate-buffered saline (PBS) for $0,24,48$ or $72 \mathrm{~h}$. The cells were supplemented with $0.5 \mu \mathrm{g} / \mu \mathrm{l}$ MTT and cultured for a further $4 \mathrm{~h}$, followed by treatment with dimethyl sulfoxide for $10 \mathrm{~min}$. The absorbance of the samples was measured at $570 \mathrm{~nm}$ using an iMark platereader (Bio-Rad Laboratories, Hercules, CA, USA).

Cell cycle analysis. The BGC823 cells infected with pSUPER-IGF-IR-siRNA2 or pSUPER-control-siRNA2, or treated with PBS, were fixed with $70 \%$ ice-cold ethanol at $4^{\circ} \mathrm{C}$ overnight. The cells were then treated with RNase A (Sigma-Aldrich, St. Louis, MO, USA) at $37^{\circ} \mathrm{C}$ for $30 \mathrm{~min}$ and propidium iodide (PI; Sigma-Aldrich) at $4^{\circ} \mathrm{C}$ for $1 \mathrm{~h}$. The DNA content of the cells was assessed using a FACSCalibur flow cytometer (BD Biosciences, Franklin Lakes, NJ, USA) and the data were analyzed using Modfit 3.0 DNA software (BD Biosciences, Franklin Lakes, NJ, USA).

PI staining for apoptosis analysis. The BGC823 cells treated with the indicated siRNAs, or PBS, were incubated with $20 \mu \mathrm{g} / \mathrm{ml}$ RNase A and stained with $50 \mu \mathrm{g} / \mathrm{ml}$ PI solution. A total of 500 cells were randomly counted under a microscope (Axio observer Z1; Zeiss Meditec, Jena, Germany). The apoptotic rate was calculated using the following formula: Rate of cell death $=$ stained cells/total cells .

DNA laddering analysis. The cells infected with the siRNAs, or treated with PBS, were treated with Tris-NaCl-EDTA buffer, containing proteinase $\mathrm{K}$, at $55^{\circ} \mathrm{C}$ overnight. Genomic DNA was isolated from the cells using DNA purification kits (Life Technologies, Carlsbad, CA, USA) and fractionated by $2 \%$ agarose gel electrophoresis.

Wound healing assay. The cells were infected with the specified siRNAs, or treated with PBS for $48 \mathrm{~h}$, prior to being seeded in a fibronectin-coated 6 well plate and cultured until confluent. The cells were then cultured in serum-free DMEM and a straight scratch was made using a $200 \mu$ l pipette tip.
The width of the scratch was observed and recorded using a microscope, at 0, 6, 12, 24 and $36 \mathrm{~h}$. Cells of three independent wound areas were counted. A minimum of three wells were counted per experiment.

Transwell cell invasion assay. Transwell chambers were sterilized by UV treatment, and the inserts and PVDF membrane were coated with Matrigel ${ }^{\circledR}$ matrix (Life Technologies). The cells $\left(1 \times 10^{5}\right)$, in serum-free media, were plated in the upper wells of the chambers, and media supplemented with 10\% FBS was added to the lower wells. Following a $24 \mathrm{~h}$ incubation, the cells on the Matrigel ${ }^{\circledR}$ side of the chambers were removed using a cotton swab. The inserts were fixed in methanol and stained using $0.2 \%$ crystal violet staining solution (Life Technologies).

Statistical analysis. The data are expressed as the means \pm standard deviation. Statistical differences were evaluated using an unpaired student's t test using SPSS version 15.0 (SPSS Inc., Chicago, IL, USA) software. A value of $\mathrm{P}<0.05$ was considered to indicate a statistically significant difference.

\section{Results}

RNAi-mediated IGF-1R silencing inhibits the growth of $B G C 823$ gastric cancer cells. An MTT assay was performed to determine whether silencing of IGF-1R expression influenced gastric cancer cell growth. The cells were infected with pSUPER-IGF-IR-siRNA2 or pSUPER-control-siRNA2, or treated with PBS, for 0, 24, 48 and $72 \mathrm{~h}$. Knockdown of IGF-1R expression for $24 \mathrm{~h}$ did not affect cell growth, as compared with the control siRNA and PBS groups. However, IGF-1R ablation for 48 to $72 \mathrm{~h}$, significantly reduced cell growth by 62.15 and $59.82 \%$, respectively (Table I and Fig. 1). This observation indicates that the greatest effects of IGF-1R expression knockdown on cell growth inhibition were achieved $48 \mathrm{~h}$ post-infection.

$R N A i$-mediated IGF-1R silencing leads to $G_{1}$ arrest in $B G C 823$ cells. To determine whether silencing of IGF-1R expression affected the progression of the cell cycle a flow cytometric analysis was performed. The cells were fixed with ethanol $48 \mathrm{~h}$ post-infection, stained with PI and subjected to fluorescence-activated cell sorting. The percentages of the IGF-1R-depleted cells in the $\mathrm{G}_{0} / \mathrm{G}_{1}, \mathrm{~S}$ and $\mathrm{G}_{2} / \mathrm{M}$ phases were $59.42,37.83$ and $3.71 \%$, respectively (Table II and Fig. 2). The control cells, either transfected with control siRNA or treated with PBS, had a significantly lower $\mathrm{G}_{0} / \mathrm{G}_{1}$ cell population and higher S population (Table II and Fig. 2). These data demonstrate that knockdown of IGF-1R expression results in $\mathrm{G}_{1}$ cell cycle arrest, and a subsequent reduction in the $\mathrm{S}$ phase population, in gastric cancer cells.

RNAi-mediated IGF-1R silencing promotes BGC823 cell apoptosis. An accumulated sub- $\mathrm{G}_{1}$ population was observed in response to IGF-1R expression knockdown, suggesting an increased number of apoptotic cells (Fig. 2). To further confirm whether IGF-1R ablation triggered apoptosis in gastric cancer cells, PI staining and microscopic analysis were performed. Living cells with an intact cytomembrane are resistant to PI staining; however, apoptotic cells are easily stained. The 
Table I. Silencing of insulin-like growth factor-1 receptor (IGF-1R) affects BGC823 gastric cancer cell proliferation, as determined by an MTT assay $(n=3)$.

\begin{tabular}{lcrrr}
\hline & \multicolumn{3}{c}{ Inhibition (\%) } \\
\cline { 2 - 5 } & $0 \mathrm{~h}$ & $24 \mathrm{~h}$ & $48 \mathrm{~h}$ & $72 \mathrm{~h}$ \\
\hline pSUPER-IGF-IR-siRNA2 & $7.62 \pm 0.43$ & $8.84 \pm 0.36$ & $62.15 \pm 0.98$ & $59.82 \pm 0.68$ \\
pSUPER-Control-siRNA & $7.39 \pm 0.26$ & $8.28 \pm 0.20$ & $8.07 \pm 0.33$ & $7.95 \pm 0.25$ \\
PBS & $7.68 \pm 0.32$ & $7.96 \pm 0.16$ & $8.13 \pm 0.29$ & $7.85 \pm 0.26$ \\
\hline
\end{tabular}

siRNA, small interfering RNA; PBS, phosphate-buffered saline.

Table II. Silencing of insulin-like growth factor-1 receptor (IGF-1R) affects BGC823 gastric cancer cell cycle progression (n=3).

\begin{tabular}{lccr}
\hline & & \multicolumn{3}{c}{ Cell cycle phases $(\%)$} \\
\cline { 2 - 4 } & $\mathrm{G}_{1} / \mathrm{G}_{0}$ & $\mathrm{~S}$ & $\mathrm{G}_{2} / \mathrm{M}$ \\
\hline pSUPER-IGF-IR-siRNA2 & $59.42 \pm 4.01$ & $37.83 \pm 2.13$ & $3.71 \pm 0.18$ \\
pSUPER-control-siRNA & $19.72 \pm 1.61$ & $50.33 \pm 4.91$ & $9.09 \pm 0.62$ \\
PBS & $14.33 \pm 2.15$ & $55.21 \pm 3.81$ & $9.64 \pm 0.71$ \\
\hline
\end{tabular}

siRNA, small interfering RNA; PBS, phosphate-buffered saline.

percentages of living cells in the IGF-1R siRNA, control siRNA and PBS groups were 8.43, 49.72 and 47.53\%, respectively (Fig. 3). These results indicate that IGF-1R ablation was capable of inducing apoptosis. A DNA laddering analysis was also conducted and IGF-1R expression knockdown dramatically enhanced the formation of a DNA ladder, which could barely be seen in the control cells (Fig. 3D). These results demonstrate that silencing of IGF-1R expression induces gastric cancer cell apoptosis.

RNAi-mediated IGF-IR silencing inhibits migration of $B G C 823$ cells. Wound-healing assays were conducted to assess the migratory ability of BGC823 cells in response to IGF-1R ablation. IGF-1R ablation markedly suppressed cell motility at $36 \mathrm{~h}$ post-infection. The control siRNA or PBS treated cells migrated to heal the wound areas, whereas the IGF-1R-depleted cells were incapable of migrating (Fig. 4A-C). Furthermore, the cells of the wound areas were counted, and the number of cells were significantly lower in the IGF-1R depletion group, as compared with the control groups (Fig. 4D). These results indicate that suppression of IGF-1R expression inhibits gastric cancer cell motility.

RNAi-mediated IGF-1R silencing suppresses invasion of $B G C 823$ cells. An in vitro Transwell assay was used to determine whether IGF-1R ablation would affect gastric cancer cell invasion (Fig. 5A-C). The average number of invasive IGF-1R-depleted cells was 98.33 (Fig. 5D), which was significantly reduced, as compared with the control siRNA (128.33) and PBS groups (135.33) (Fig. 5D). These results suggest that IGF-1R depletion may also prevent gastric cancer cell invasion.

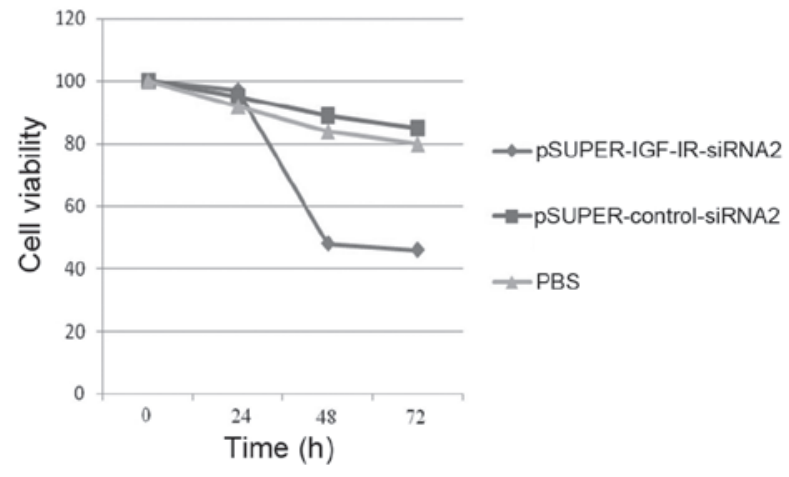

Figure 1. Silencing of insulin-like growth factor-1 receptor (IGF-1R) inhibits BGC823 gastric cancer cell growth. The cells were infected with pSUPER-IGF-IR-siRNA2 or pSUPER-control-siRNA2, or treated with phosphate-buffered saline (PBS) as indicated for 024,48 and $72 \mathrm{~h}$, followed by an MTT assay to detect cell viability. All of the experiments were repeated three times. ${ }^{*} \mathrm{P}<0.05$ vs. pSUPER-control-siRNA2.

\section{Discussion}

The aim of the present study was to determine whether IGF-1R may be a potential therapeutic target for gastric cancer. RNAi technology was used to silence endogenous IGF-1R expression, and the physiological outcomes were examined in BGC823 gastric cancer cells. Ablation of IGF-1R resulted in repressed cell growth, accumulated $\mathrm{G}_{1}$-phase population, enhanced apoptosis, and impaired abilities of cell motility and invasion. These results suggested a tumor-inhibitory function of IGF-1R-targeting siRNA; however, it remains to be elucidated whether siRNA-mediated IGF-1R ablation is able to inhibit gastric tumor 

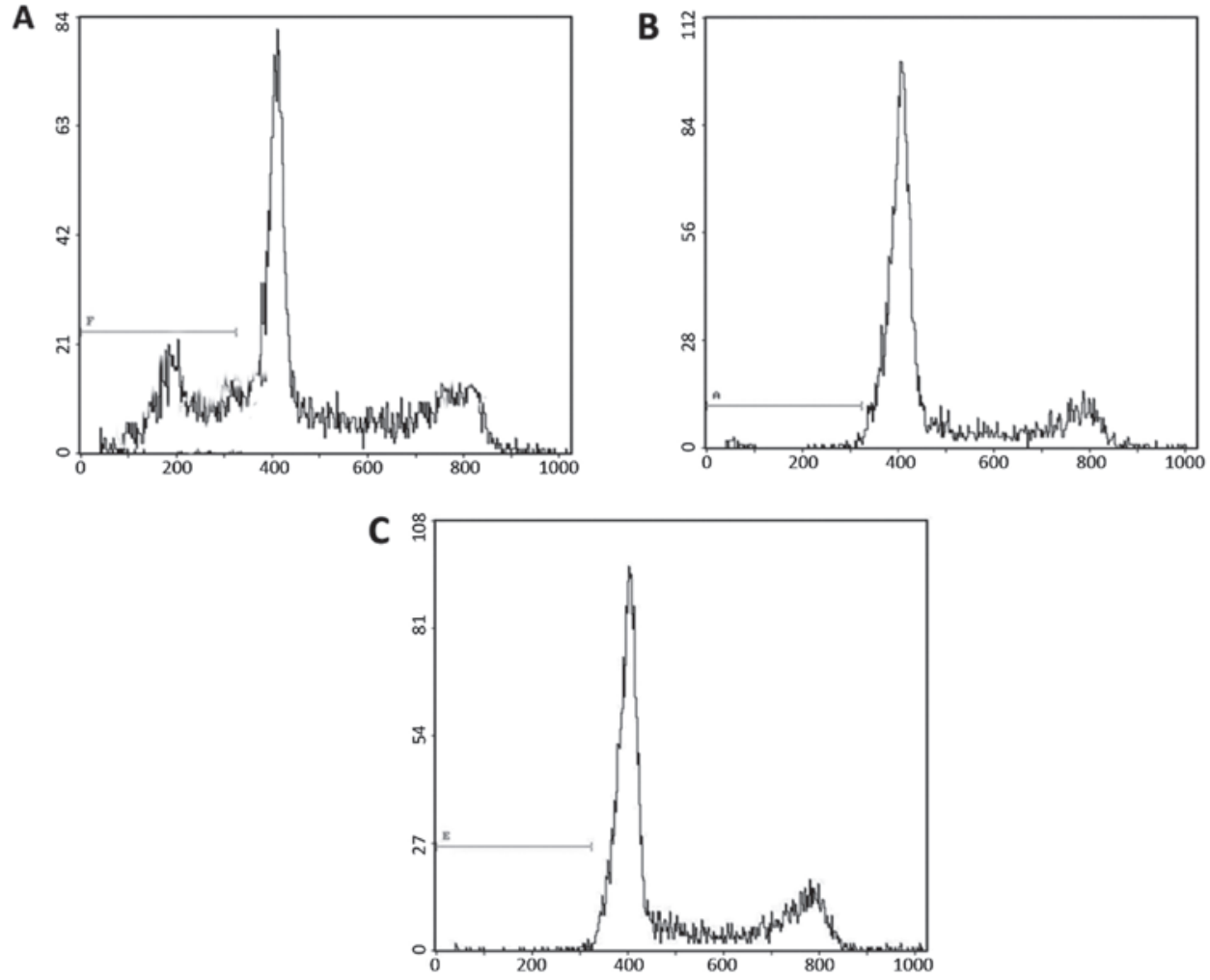

Figure 2. Silencing of insulin-like growth factor-1 receptor (IGF-1R) results in accumulated $\mathrm{G}_{1}$ and sub-G $\mathrm{G}_{1}$ population in BGC823 gastric cancer cells. The cells were infected with (A) pSUPER-IGF-IR-siRNA2 or (B) pSUPER-control-siRNA2, or (C) treated with phosphate-buffered saline for $48 \mathrm{~h}$ and subjected to flow cytometric analysis.
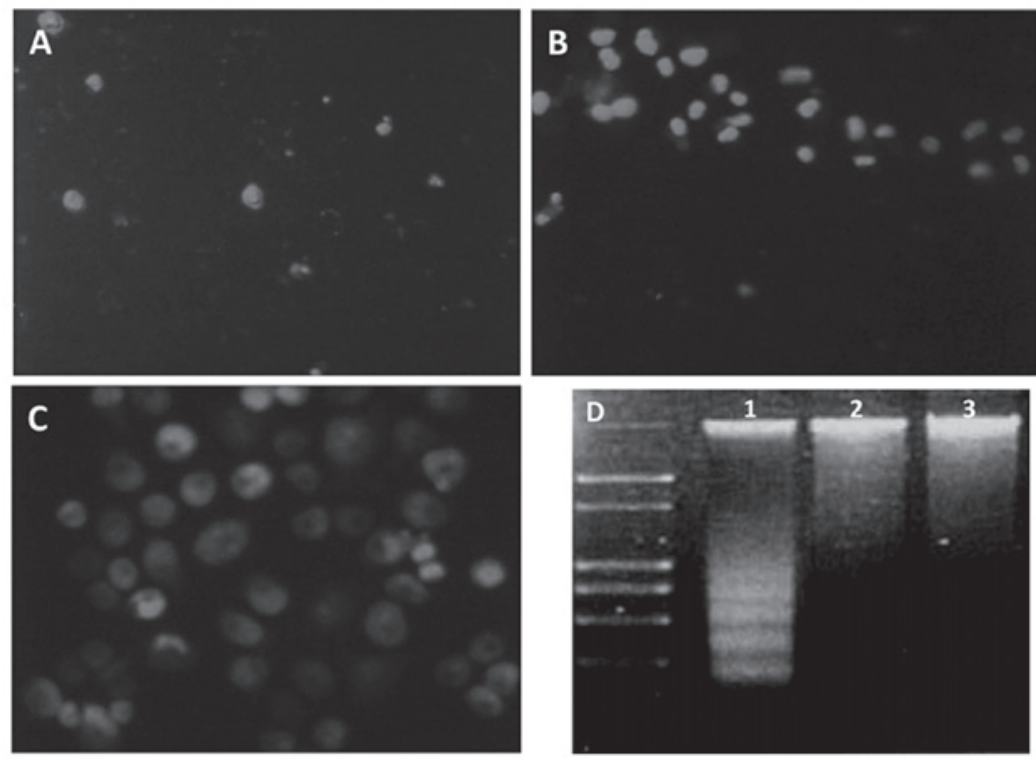

Figure 3. Silencing of insulin-like growth factor-1 receptor (IGF-1R) promotes apoptosis in BGC823 gastric cancer cells. (A-C) propidium iodide staining or (D) DNA laddering analysis. The cells were infected with (A and lane 1 of D) pSUPER-IGF-IR-siRNA2 or (B and lane 2 of D) pSUPER-control-siRNA2, or (C and lane 3 of D) treated with phosphate-buffered saline for $48 \mathrm{~h}$ and subjected to PI staining or DNA laddering analysis. Magnification, x100. siRNA, small interfering RNA.

growth in vivo. Therefore, delivery of IGF-1R-targeting siRNA in a mouse model of gastric cancer or RNAi-based xenografts may be a promising area of future study.

Overexpression of IGF-1R has been regarded as a typical hallmark of numerous human cancers, and various tumor suppressors, including p53 family proteins $(14,15)$, breast cancer $1(16,17)$, Von Hippel-Lindau protein (18), Wilms' tumor $1(19,20)$, have been shown to negatively regulate IGF-1R transcription (4). These results imply that IGF-1R may be a therapeutic target for human cancers. 

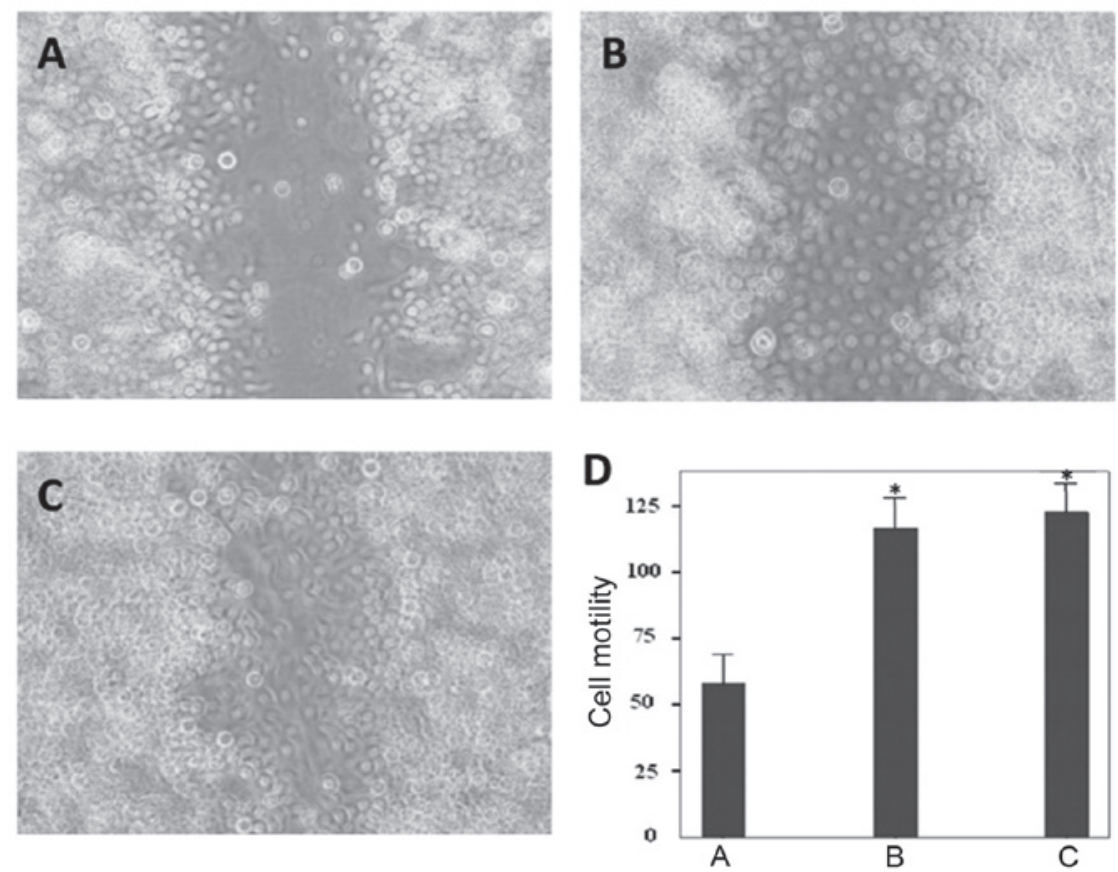

Figure 4. Silencing of insulin-like growth factor-1 receptor (IGF-1R) suppresses BGC823 gastric cancer cell motility. The cells were infected with (A) pSUPER-IGF-IR-siRNA2 or (B) pSUPER-control-siRNA2, or (C) treated with phosphate-buffered saline for $48 \mathrm{~h}$ and subjected to a wound-healing assay Magnification, $x 100$. (D) In each group, cells of three independent wound areas were counted. The data represent the means \pm standard deviation. "P $<0.05 \mathrm{vs}$ pSUPER-IGF-IR-siRNA2. siRNA, small interfering RNA.
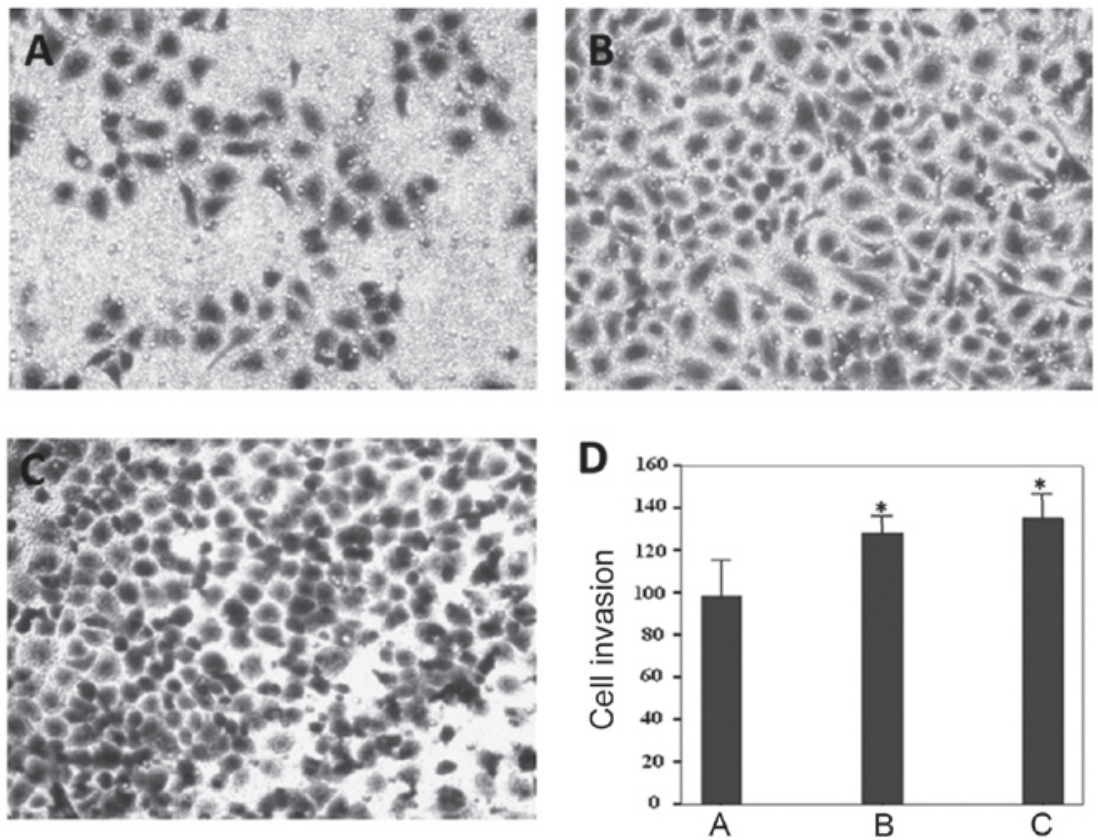

Figure 5. Silencing of insulin-like growth factor-1 receptor (IGF-1R) restrains BGC823 gastric cancer cell invasion. The cells were infected with (A) pSUPER-IGF-IR-siRNA2 or (B) pSUPER-control-siRNA2, or (C) treated with phosphate-buffered saline for $48 \mathrm{~h}$ and subjected to a Transwell cell invasion assay. Magnification, x100. (D) The average invasive cell numbers of three independent experiments. The data represent the means \pm standard deviation. ${ }^{*} \mathrm{P}<0.05$ vs pSUPER-IGF-IR-siRNA2. siRNA, small interfering RNA.

RNAi-based IGF-1R repression has previously been applied to sensitize drug-resistant cancer cells harboring mutated p53 (21). Furthermore, it has previously been demonstrated that administering a half maximal inhibitory concentration dose of Adriamycin ${ }^{\circledR}$, with siRNA targeting IGF-1R, considerably reduced cell growth in liver cancer cells (21). However, it remains unknown whether IGF-1R depletion may be detrimental to cell proliferation and invasion in gastric cancer. A seminal study previously demonstrated that IGF-1R prompts tumor growth and survival in gastric cancer, and a dominant-negative fragment of IGF-1R may suppress IGF-1R-induced tumorigenicity and trigger apoptosis (22). Considering the results of the present study, developing small molecules, including lead compounds, short peptides or 
siRNAs, that target IGF-1R may be a potential and promising strategy for gastric cancer therapy.

Mechanistically, IGF ligands, including IGF1 and IGF2, can be either generated from remote sites and delivered through circulation, or locally produced (23). These ligands specifically bind to IGF-1R leading to stimulation of its intrinsic tyrosine kinase activity, consequently eliciting intracellular signaling that controls cell proliferation and survival (24). Two pathways are highly responsive following the interaction of IGF1/IGF2 and IGF-1R. The PI3K-AKT-mTOR pathway may be activated and substantially promotes global protein synthesis, which supports enhanced cell proliferation. In addition, IGF1/IGF2-IGF-1R binding also triggers the RAF-MAPK cascade which is involved in numerous cellular processes, including proliferation, differentiation, mitosis, cell survival, and apoptosis (25). Therefore, abrogation of IGF1/IGF2-IGF-1R signaling by RNAi-based technology may impair both PI3K-AKT-mTOR and RAF-MAPK pathways, thus suppressing tumor cell growth.

In conclusion, the present study is the first, to the best of our knowledge, to demonstrate that siRNA-mediated IGF-1R expression silencing markedly reduces the malignant properties of gastric cancer cells. These results suggest that targeting IGF-1R by siRNA may be an effective strategy for gastric cancer treatment and that RNAi-based therapy for gastric cancer requires further comprehensive exploration.

\section{Acknowledgements}

The authors of the present study would like to acknowledge Biomedworld for the help in editing the manuscript. The present study was supported by the Natural Science Foundation of Central South University (no. 2012QNZT135).

\section{References}

1. Salmon WD Jr and Daughaday WH: A hormonally controlled serum factor which stimulates sulfate incorporation by cartilage in vitro. J Lab Clin Med 49: 825-836, 1957.

2. Maki RG: Small is beautiful: insulin-like growth factors and their role in growth, development, and cancer. J Clin Oncol 28: 4985-4995, 2010.

3. Sell C, Rubini M, Rubin R, et al: Simian virus 40 large tumor antigen is unable to transform mouse embryonic fibroblasts lacking type 1 insulin-like growth factor receptor. Proc Natl Acad Sci USA 90: 11217-11221, 1993.

4. Werner H: Tumor suppressors govern insulin-like growth factor signaling pathways: implications in metabolism and cancer. Oncogene 31: 2703-2714, 2012.

5. Seccareccia $\mathrm{E}$ and Brodt $\mathrm{P}$ : The role of the insulin-like growth factor-I receptor in malignancy: an update. Growth Horm IGF Res 22: 193-199, 2012.

6. Fire A, Xu S, Montgomery MK, et al: Potent and specific genetic interference by double-stranded RNA in Caenorhabditis elegans. Nature 391: 806-811, 1998.
7. Deng Y, Wang CC, Choi KW, et al: Therapeutic potentials of gene silencing by RNA interference: principles, challenges, and new strategies. Gene 538: 217-227, 2014.

8. Castel SE and Martienssen RA: RNA interference in the nucleus: roles for small RNAs in transcription, epigenetics and beyond. Nat Rev Genet 14: 100-112, 2013.

9. Guo J, Evans JC and O'Driscoll CM: Delivering RNAi therapeutics with non-viral technology: a promising strategy for prostate cancer? Trends Mol Med 19: 250-261, 2013.

10. Levine AJ and Oren M: The first 30 years of p53: growing ever more complex. Nat Rev Cancer 9: 749-758, 2009.

11. Lane DP, Cheok CF and Lain S: p53-based cancer therapy. Cold Spring Harb Perspect Biol 2: a001222, 2010.

12. Oren $M$ and Rotter V: Mutant p53 gain-of-function in cancer. Cold Spring Harb Perspect Biol 2: a001107, 2010.

13. Ge J, Chen Z, Wu S, et al: Expression levels of insulin-like growth factor-1 and multidrug resistance-associated protein-1 indicate poor prognosis in patients with gastric cancer. Digestion 80: 148-158, 2009.

14. Werner H, Karnieli E, Rauscher FJ and LeRoith D: Wild-type and mutant p53 differentially regulate transcription of the insulin-like growth factor I receptor gene. Proc Natl Acad Sci USA 93: 8318-8323, 1996.

15. Nahor I, Abramovitch S, Engeland K and Werner H: The p53-family members p63 and p73 inhibit insulin-like growth factor-I receptor gene expression in colon cancer cells. Growth Horm IGF Res 15: 388-396, 2005.

16. Maor S, Yosepovich A, Papa MZ, et al: Elevated insulin-like growth factor-I receptor (IGF-IR) levels in primary breast tumors associated with BRCA1 mutations. Cancer Lett 257: 236-243, 2007

17. Maor SB, Abramovitch S, Erdos MR, Brody LC and Werner H: BRCA1 suppresses insulin-like growth factor-I receptor promoter activity: potential interaction between BRCA1 and Sp1. Mol Genet Metab 69: 130-136, 2000.

18. Yuen JS, Cockman ME, Sullivan M, et al: The VHL tumor suppressor inhibits expression of the IGF1R and its loss induces IGF1R upregulation in human clear cell renal carcinoma. Oncogene 26: 6499-6508, 2007.

19. Werner H, Re GG, Drummond IA, et al: Increased expression of the insulin-like growth factor I receptor gene, IGF1R, in Wilms tumor is correlated with modulation of IGF1R promoter activity by the WT1 Wilms tumor gene product. Proc Natl Acad Sci USA 90: 5828-5832, 1993.

20. Werner H, Shen-Orr Z, Rauscher FJ III, et al: Inhibition of cellular proliferation by the Wilms' tumor suppressor WT1 is associated with suppression of insulin-like growth factor I receptor gene expression. Mol Cell Biol 15: 3516-3522, 1995.

21. Niu J, Xu Z, Li XN and Han Z: siRNA-mediated type 1 insulin-like growth factor receptor silencing induces chemosensitization of a human liver cancer cell line with mutant P53. Cell Biol Int 31: 156-164, 2007.

22. Min Y, Adachi Y, Yamamoto H, et al: Insulin-like growth factor I receptor blockade enhances chemotherapy and radiation responses and inhibits tumour growth in human gastric cancer xenografts. Gut 54: 591-600, 2005.

23. Tian D and Kreeger PK: Analysis of the quantitative balance between insulin-like growth factor (IGF)-1 ligand, receptor, and binding protein levels to predict cell sensitivity and therapeutic efficacy. BMC Syst Biol 8: 98, 2014.

24. Denley A, Cosgrove LJ, Booker GW, Wallace JC and Forbes BE: Molecular interactions of the IGF system. Cytokine Growth Factor Rev 16: 421-439, 2005.

25. Pollak MN, Schernhammer ES and Hankinson SE: Insulin-like growth factors and neoplasia. Nat Rev Cancer 4: 505-518, 2004. 